\title{
Palatability Assessments of Beef Top Loin Steaks Sourced from Three Quality Grade/Brand Categories from Texas and Non-Texas Processing Establishments
}

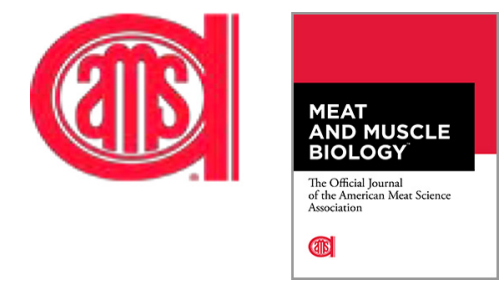

\author{
Michaela C. Till, Ashley N. Arnold, Davey B. Griffin, Daniel S. Hale, Christopher R. Kerth, \\ Rhonda K. Miller, Kerri B. Gehring, and Jeffrey W. Savell* \\ Department of Animal Science, Texas A\&M AgriLife Research, Texas A\&M University, College Station, \\ TX 77843-2471, USA \\ *Corresponding author. Email: j-savell@tamu.edu (Jeffrey W. Savell)
}

\begin{abstract}
Beef top loin steaks from Top Choice (Modest and Moderate marbling), Choice (primarily Small marbling), and Select (Slight marbling) beef strip loins from Texas and Non-Texas (Kansas, Nebraska, and Colorado) beef processing establishments were obtained to determine the role of source and USDA grade/brand category on consumer sensory panel and Warner-Bratzler shear (WBS) evaluations. The number of strip loins obtained were 58 Texas Top Choice, 54 Texas Choice, and 56 Texas Select and 60 Non-Texas Top Choice, 52 Non-Texas Choice, and 58 Non-Texas Select. There were source $\times$ USDA grade/brand category interactions for overall liking $(P=0.012)$ and tenderness liking $(P=0.002)$ in which the Texas Top Choice steaks received ratings that did not differ $(P>0.05)$ from Texas Select steaks but did differ $(P<0.05)$ from the Non-Texas Top Choice steaks. There were no $(P=0.079)$ differences in WBS values for steaks from the 2 sources even though the $P$ value approached significance. For USDA quality grade/brand category, there were differences $(P<$ $0.001)$ in WBS values, but not in the direction one might expect: Choice steaks had the lowest $(P<0.05)$ WBS values compared with those from Top Choice and Select steaks, which did not differ $(P>0.05)$ from each other. Percentage distribution of WBS values according to tenderness categories showed that all of the Top Choice and Choice steaks, regardless of source, had values that met the threshold values for Very Tender (WBS $<31.4 \mathrm{~N}$ ) or Tender $(31.4 \mathrm{~N}<\mathrm{WBS}<38.3 \mathrm{~N})$. While geographic purchasing biases may remain, these data assist in supporting informed decisions regarding palatability and consumer acceptability as functions of beef sourcing.
\end{abstract}

Key words: beef, consumer acceptability, tenderness, USDA beef grades

Meat and Muscle Biology 5(1): 7, 1-10 (2021) doi:10.22175/mmb.11471

Submitted 20 June $2020 \quad$ Accepted 3 November 2020

\section{Introduction}

In the 1990s, because of real or perceived bias against beef originating from Texas, we were asked to participate in a project designed to address this issue. The "Texas Perception Study" (Savell et al., 1996) was a collaborative effort to ascertain whether differences between beef from Texas and "Northern" plants (beef processing facilities from Kansas, Nebraska, or Colorado) existed. This differentiation between Texas and Northern establishments arose from our discussions with personnel from some of the large beef processing companies that indicated that oftentimes customers would request that beef be sourced from Northern plants rather than their establishments located in Texas.

Concerns about Texas beef focused primarily on breed type with the thought that Bos indicus breeds found in greater numbers in the Southern United States, especially in Texas, could contribute to alleged tenderness inconsistencies. There are a number of studies that document that percentage Bos indicus breeding (Huffman et al., 1990; Whipple et al., 1990; Pringle et al., 1997) or even phenotypic expression of 
the breed type (Sherbeck et al., 1996) contributes to decreased tenderness compared with Bos taurus. Feed sources were often mentioned as an additional reason for less palatable beef from Texas owing to the perception that corn feeding was limited to the Midwestern US and was not prevalent in Texas. Irrespective of the events or factors that formed the bias, a trial was needed to determine the facts about Texas beef.

The Texas Perception Study found a significant interaction between source (Texas and Out of Texas [term used rather than "Northern"]) and grade (Choice and Select) for Warner-Bratzler shear (WBS) force (Savell et al., 1996). Out of Texas Choice steaks had the lowest $(P<0.05)$ WBS values $(28.5 \mathrm{~N})$ compared with either Choice $(32.2 \mathrm{~N})$ or Select $(31.2 \mathrm{~N})$ steaks from Texas. Select steaks from either source did not differ in WBS values. Fortunately for those who marketed Select beef, source was not an issue, as most WBS values (regardless of source or grade) were in a range that were thought to be "acceptable" at least at the time $(35.6 \mathrm{~N})$.

New concerns have been expressed over potential implications of geographic sources on branded beef. Branded beef programs, such as Certified Angus Beef (Certified Angus Beef LLC, c2021), have grown substantially during the 21 st century, which is evidenced by the fact that by 2019 , the percentage of fed cattle qualifying for the Certified Angus Beef brand exceeded the number of fed cattle grading Select (Reiman, 2019). If negative connotations exist for any source of beef, their impact will likely be greatest for brands with taste and tenderness claims as customers routinely pay more for premium products as reflected in US Department of Agriculture (USDA) Market News reports for prices of branded boxed beef cuts (USDA, 2020b) and for premiums and discounts for slaughter cattle (USDA, 2020c).

Nearly 25 y after our initial work looking at tenderness differences owing to geographical locations (Savell et al., 1996), similar questions are being asked. This time, the major issue relates to differences in product quality level for premium Choice programs that focus primarily on Modest and Moderate marbling scores (often referred to as Top Choice, Upper 2/3's Choice, Premium Choice, etc.). Therefore, in the present study, we evaluated beef top loin steaks from 3 USDA quality grade/brand categories-(1) Top Choice, (2) Choice, and (3) Select—and 2 geographic sources-establishments (1) from Texas and (2) from Colorado, Kansas, and Nebraska (termed Non-Texas) - to offer some insight into how these factors impact palatability as measured by consumer sensory ratings and WBS force values.

\section{Materials and Methods}

\section{Product selection}

We collaborated with a number of foodservice suppliers and case-ready manufacturing facilities to source the products for this project. Label information located on boxes and/or vacuum packages was used to obtain the USDA (2020a) establishment numbers for determining geographic sources, the USDA (2017) beef grades, and the USDA ([date unknown]) branded beef programs. All products obtained followed the appropriate post-packing aging protocols for each foodservice supplier/case-ready manufacturing facility before steaks were obtained for this study.

Beef was obtained from USDA processing establishments in 4 US states to represent 2 geographic sources: (1) from Texas (4 establishments) and (2) from Colorado (2 establishments), Kansas (2 establishments), and Nebraska (3 establishments), which collectively were termed "Non-Texas" rather than "Northern" in this study. Selected beef products represented 3 USDA grade/brand categories: Top Choice (branded programs that require Modest and Moderate marbling scores to qualify), Choice (primarily Small marbling scores), and Select (Slight marbling scores).

Institutional Meat Purchase Specifications (IMPS), as described by USDA (2014) and North American Meat Institute (2014), were used for nomenclature purposes. Beef loin, strip loin, boneless (IMPS 180) subprimals were used for this project. Limited availability of the grade/brand categories from the different sources prevented equal representation in all selection cells. From the Texas establishments, Top Choice $(n=58)$, Choice $(n=54)$, and Select $(n=56)$ strip loins were obtained, and from the Non-Texas establishments, Top Choice $(n=60)$, Choice $(n=52)$, and Select $(n=$ 58) strip loins were obtained.

Strip loins were removed from their individual vacuum bags, and after facing, three 2.54-cm-thick steaks were taken from the anterior end to create strip loin, center-cut, boneless (IMPS 1180A) steaks, 2 for sensory panel and 1 for WBS evaluation. The 3 steaks were placed individually in unsealed vacuum bags and were transported in insulated coolers with refrigerant material to Texas A\&M University Rosenthal Meat Science and Technology Center (College Station, TX). Upon arrival, steaks were packaged individually 
in 2.0-mil Sealed Air Food Care vacuum bags (Item No. B2470, Sealed Air, Charlotte, NC) with an oxygen transmission rate of 3 to $6\left(\left[\mathrm{~cm}^{3}(\mathrm{STP}) /\left(\mathrm{m}^{2}-24 \mathrm{~h}-\mathrm{atm}\right)\right]\right.$ at $0 \%$ relative humidity, $\left.4.4^{\circ} \mathrm{C}\right)$ using an UltraVac Double Chamber Vacuum Packaging Machine (Model 2100-D; Kansas City, MO) at approximately $-46 \mathrm{kPa}$, and steaks were frozen $\left(-40^{\circ} \mathrm{C}\right)$.

\section{Cooking method}

Steaks were thawed at approximately $2^{\circ} \mathrm{C}$ to $4^{\circ} \mathrm{C}$ for $48 \mathrm{~h}$ and weighed, and initial internal temperatures were recorded before being cooked on grated, open-hearth, nonstick electric grills (Hamilton Beach Indoor/ Outdoor Grill, Southern Pines, NC) preheated to approximately $177^{\circ} \mathrm{C}$. A thermocouple reader (Omega HH506A, Stanford, CT) was used to monitor internal steak temperature with a $0.02-\mathrm{cm}$ diameter, copper constantan Type-T thermocouple wire (Omega). Once steaks reached an internal temperature of $35^{\circ} \mathrm{C}$, they were flipped and were removed when a final internal temperature of $70^{\circ} \mathrm{C}$ was reached. Thermocouples were removed from each steak, and cook times and steak weights were recorded. Cooked steaks assigned to sensory evaluation were placed in a food warmer set at $60^{\circ} \mathrm{C}$ (Alto-Shaam, Model 750-TH-II, Milwaukee, WI) for no longer than 20 min before serving panelists. Cooked steaks destined for WBS force evaluation were placed on trays in a single layer, covered with plastic film, and stored $\left(2^{\circ} \mathrm{C}\right.$ to $\left.4^{\circ} \mathrm{C}\right)$ for 16 to $18 \mathrm{~h}$.

\section{Consumer panel}

Consumer panel procedures were approved by the Texas A\&M Institutional Review Board (Protocol Number: IRB2016-0328M). Consumer panelists ( $n=$ 335) were recruited from the Bryan/College Station area using an existing database and email list servers, and their demographics and consumption patterns are presented in Tables 1 and 2, respectively.

Steaks cooked as previously described were cut into cuboidal portions (approximately $1.27 \mathrm{~cm} \times 1.27$ $\mathrm{cm} \times$ steak thickness) and served warm to consumer panelists in individual booths equipped with red theater gel lights. Samples were served in a random order and identified with 3-digit codes. Consumer sensory panels were initially designed to be completed in 14 sessions, with each session comprising 6 groups of 4 panelists each. Therefore, each panelist assessed up to 6 samples per session. Panelists were provided Nabisco Unsalted tops Premium Saltine Crackers (Kraft Foods Global Inc., East Hanover, NJ) and double-distilled deionized water to use as palate cleansers between samples.
Table 1. Demographic attributes of consumer panelists ( $n=335$ consumers)

\begin{tabular}{|c|c|}
\hline Item & Frequency $(\%)$ \\
\hline \multicolumn{2}{|l|}{ Gender } \\
\hline Male & 42.4 \\
\hline Female & 57.3 \\
\hline No response & 0.3 \\
\hline \multicolumn{2}{|l|}{ Age, $y$} \\
\hline$<20$ & 11.0 \\
\hline $21-25$ & 31.9 \\
\hline $26-35$ & 24.8 \\
\hline $36-45$ & 8.7 \\
\hline $46-55$ & 11.6 \\
\hline $56-65$ & 6.0 \\
\hline$\geq 66$ & 6.0 \\
\hline \multicolumn{2}{|l|}{ Current working status } \\
\hline Not employed & 6.3 \\
\hline Full time & 43.3 \\
\hline Part time & 17.0 \\
\hline Student & 41.8 \\
\hline No response & 0.6 \\
\hline \multicolumn{2}{|l|}{ Household income, US\$ } \\
\hline$<25,000$ & 26.9 \\
\hline $25,000-49,999$ & 23.3 \\
\hline $50,000-74,999$ & 15.8 \\
\hline $75,000-99,999$ & 14.0 \\
\hline$\geq 100,000$ & 19.7 \\
\hline No response & 0.3 \\
\hline \multicolumn{2}{|c|}{ Food allergies or dietary restrictions? } \\
\hline No & 94.6 \\
\hline Yes & 5.1 \\
\hline No response & 0.3 \\
\hline \multicolumn{2}{|c|}{$\begin{array}{l}\text { Do you or any of your immediate family } \\
\text { work for a market research firm, advertising } \\
\text { firm, or food manufacturing company? }\end{array}$} \\
\hline No & 99.4 \\
\hline Yes & 0.6 \\
\hline \multicolumn{2}{|l|}{ Ethnicity } \\
\hline Caucasian & 74.3 \\
\hline Hispanic & 12.5 \\
\hline Asian or Pacific Islander & 7.5 \\
\hline Black & 5.4 \\
\hline American Indian & 1.2 \\
\hline Other & 1.5 \\
\hline No response & 0.3 \\
\hline
\end{tabular}

Panelists were asked to characterize steak sample attributes using 9-point scales $(1=$ dislike extremely; $9=$ like extremely) for overall liking, flavor liking, juiciness liking, and tenderness liking.

\section{WBS force}

Chilled steaks were equilibrated to room temperature (approximately $30 \mathrm{~min}$ ) before being trimmed of 
Table 2. Consumption patterns of consumer panelists ( $n=335$ consumers)

\begin{tabular}{|c|c|}
\hline Item & Frequency $(\%)$ \\
\hline \multicolumn{2}{|l|}{ Do you eat meat? } \\
\hline No & 0.0 \\
\hline Yes & 100.0 \\
\hline \multicolumn{2}{|l|}{ Meat types consumed } \\
\hline Chicken & 98.2 \\
\hline Pork & 92.8 \\
\hline Beef & 100.0 \\
\hline Fish & 88.9 \\
\hline \multicolumn{2}{|l|}{ Overall beef consumption } \\
\hline Daily & 6.6 \\
\hline 5 or more times per wk & 14.0 \\
\hline 3 or more times per wk & 48.8 \\
\hline 1 time per wk & 25.8 \\
\hline 1 time every 2 wk & 3.9 \\
\hline Less than once every $2 \mathrm{wk}$ & 0.6 \\
\hline No response & 0.3 \\
\hline \multicolumn{2}{|l|}{ At-home beef consumption } \\
\hline 0 times per wk & 6.6 \\
\hline 1 time per wk & 28.7 \\
\hline 2 times per wk & 31.1 \\
\hline 3 times per wk & 21.6 \\
\hline 4 times per wk & 3.6 \\
\hline 5 or more times per wk & 7.5 \\
\hline No response & 0.9 \\
\hline \multicolumn{2}{|c|}{ In-restaurant beef consumption } \\
\hline 0 times per wk & 4.5 \\
\hline 1 time per wk & 41.1 \\
\hline 2 times per wk & 25.7 \\
\hline 3 times per wk & 17.6 \\
\hline 4 times per wk & 5.4 \\
\hline 5 or more times per wk & 4.2 \\
\hline No response & 1.5 \\
\hline \multicolumn{2}{|c|}{ Preferred degree of doneness for beef } \\
\hline Rare & 3.6 \\
\hline Medium rare & 42.4 \\
\hline Medium & 24.8 \\
\hline Medium well & 22.1 \\
\hline Well done & 8.4 \\
\hline No response & 0.3 \\
\hline \multicolumn{2}{|c|}{ Purchase tendencies for beef } \\
\hline Grass-fed & 18.5 \\
\hline Traditional & 82.7 \\
\hline Aged & 7.2 \\
\hline Organic & 6.3 \\
\hline No response & 1.2 \\
\hline
\end{tabular}

visible fat and heavy connective tissue to expose muscle fiber orientation. From each steak, six $1.3-\mathrm{cm}$ cores were removed parallel to the muscle fibers using a handheld coring device. Cores were sheared once, perpendicular to the muscle fibers, using a United
Testing machine (United SSTM-500, Huntington Beach, CA) at a cross-head speed of $200 \mathrm{~mm} / \mathrm{min}$ using an $10.0-\mathrm{kg}$ load cell, and a $1.02-\mathrm{cm}$-thick V-shape blade with a $60^{\circ}$ angle and a half-round peak. The peak shear force was recorded, and the mean peak shear force values were used for statistical analysis.

\section{Statistical analysis}

While addressing reviewer comments on the original manuscript submission, we identified a deviation from the planned steak allocation. The project was designed to use 2 steaks from each subprimal for sensory panel evaluations and 1 steak for shear force analysis. Instead, the steaks were actually divided, in near-equal proportions, between sensory panel and shear force. We are not able to correct the steak allocation mistake, but we are able to address the allocation of steaks from each subprimal. Some subprimals had a single data point for sensory panel and for shear force evaluations, whereas others had multiple data points for sensory and/or shear force. For subprimals with multiple data points, each subprimal observation was assigned a random number, and the steak with the lowest random number was used for statistical analysis. This process ensured that data from 1 steak for sensory panel and 1 steak for shear force for each subprimal were represented.

All data were analyzed using JMP Pro version 15.0.0 (SAS Institute Inc., Cary, NC). Frequencies were determined for consumer demographics and consumption patterns. For all other data types, the mixed model function of JMP was used with source, grade, and their interaction as fixed effects. In accordance with the American Meat Science Association (2016) sensory guidelines, full models for consumer panelist responses for each sensory attribute also included group and order as a random effects with session and day identified as blocking factors. Models were reduced as appropriate, and where analysis of variance testing indicated significance $(P<0.05)$, least-squares means were separated using a Student $t$ test with an alpha level of 0.05 .

\section{Results and Discussion}

\section{Cooking yields and cooking times}

Cooking yields and cooking times are reported in Tables 3 (sensory panel steaks) and 4 (WBS steaks). For the sensory panel steaks, source did not impact 
Table 3. Least-squares means for cook times of sensory panel steaks stratified by source ${ }^{1}$ and USDA quality grade/brand category ${ }^{2}$

\begin{tabular}{|c|c|c|c|c|c|}
\hline & & Cook yield & & Cook time & \\
\hline & & & & (1101) & $\mathrm{SE}$ \\
\hline \multicolumn{6}{|l|}{ Source } \\
\hline Texas establishments & 168 & 82.6 & 0.37 & 19.9 & 0.46 \\
\hline Non-Texas establishments & 170 & 82.2 & 0.37 & 20.9 & 0.45 \\
\hline$P$ value & & 0.4540 & & 0.113 & \\
\hline \multicolumn{6}{|l|}{$\begin{array}{l}\text { USDA quality grade/ } \\
\text { brand category }\end{array}$} \\
\hline Top Choice & 118 & $83.6^{\mathrm{a}}$ & 0.44 & $18.6^{\mathrm{c}}$ & 0.54 \\
\hline Choice & 106 & $81.4^{\mathrm{b}}$ & 0.46 & $20.2^{\mathrm{b}}$ & 0.57 \\
\hline Select & 114 & $82.3^{\mathrm{b}}$ & 0.45 & $22.3^{\mathrm{a}}$ & 0.55 \\
\hline$P$ value & & 0.002 & & $<0.001$ & \\
\hline
\end{tabular}

${ }^{1}$ Beef strip loins were obtained from Texas establishments or from NonTexas establishments (Kansas, Nebraska, or Colorado).

${ }^{2}$ USDA quality grade/brand category: Top Choice $=$ branded programs that require Modest and Moderate marbling scores to qualify; Choice = primarily Small marbling scores; Select $=$ Slight marbling.

${ }^{3}$ Standard error of the mean.

${ }^{\mathrm{a}-\mathrm{c}}$ Means within a column without a common superscript letter differ $(P<0.05)$.

$(P>0.05)$ either cook yield or cook time, but USDA quality grade/brand category did impact cook yield $(P=0.002)$ and cook time $(P<0.001)$. Top Choice steaks had greater $(P<0.05)$ cook yields than either the Choice or Select steaks. For cook time, Select steaks required the longest $(P<0.05)$ cooking times, Top Choice steaks the shortest $(P<0.05)$, and Choice steaks intermediate to the two.

Source did not impact either cook yield $(P=0.876)$ or cook time $(P=0.779)$ for the WBS steaks (Table 4$)$. USDA quality grade/brand category did influence cook yield $(P=0.044)$ and cook time $(P<0.001)$, with the Top Choice steaks having the greatest cook yield $(P<$ $0.05)$ and Select steaks requiring the longest $(P<0.05)$ cook time compared with the other categories. Luchak et al. (1998) found that Select top loin steaks required longer cooking times than Choice top loin steaks.

\section{Consumer sensory panel}

Main effect means for flavor liking and juiciness liking (Table 5) showed that juiciness liking ratings were not affected by either source $(P=0.904)$ or USDA quality grade/brand category $(P=0.246)$. There were no $(P=0.665)$ differences in flavor ratings for steaks from Texas versus Non-Texas establishments, but flavor liking approached significance $(P=0.064)$ for the USDA quality grade/brand category. Previous research has shown differences in
Table 4. Least-squares means for cook yields and cook times of Warner-Bratzler shear steaks stratified by source ${ }^{1}$ and USDA quality grade/brand category ${ }^{2}$

\begin{tabular}{|c|c|c|c|c|c|}
\hline Item & $n$ & $\begin{array}{c}\text { Cook yield } \\
(\%)\end{array}$ & SEM $^{3}$ & $\begin{array}{l}\text { Cook time } \\
\text { (min) }\end{array}$ & SEI \\
\hline \multicolumn{6}{|l|}{ Source } \\
\hline Texas establishments & 173 & 83.7 & 0.40 & 20.9 & 0.49 \\
\hline Non-Texas establishments & 169 & 83.6 & 0.41 & 20.7 & 0.50 \\
\hline$P$ value & & 0.876 & & 0.779 & \\
\hline \multicolumn{6}{|l|}{$\begin{array}{l}\text { USDA quality grade/ } \\
\text { brand category }\end{array}$} \\
\hline Top Choice & 117 & $84.7^{\mathrm{a}}$ & 0.49 & $19.0^{\mathrm{b}}$ & 0.60 \\
\hline Choice & 112 & $83.3^{\mathrm{b}}$ & 0.50 & $19.6^{\mathrm{b}}$ & 0.61 \\
\hline Select & 113 & $83.1^{\mathrm{b}}$ & 0.48 & $23.8^{\mathrm{a}}$ & 0.61 \\
\hline$P$ value & & 0.044 & & $<0.001$ & \\
\hline
\end{tabular}

${ }^{1}$ Beef strip loins were obtained from Texas establishments or from NonTexas establishments (Kansas, Nebraska, or Colorado).

${ }^{2}$ USDA quality grade/brand category: Top Choice = branded programs that require Modest and Moderate marbling scores to qualify; Choice = primarily Small marbling scores; Select $=$ Slight marbling.

${ }^{3}$ Standard error of the mean.

a,b Means within a column without a common superscript letter differ $(P<0.05)$.

Table 5. Least-squares means of consumer panelists' sensory ratings ${ }^{1}$ stratified by source $^{2}$ and USDA quality grade/brand category ${ }^{3}$

\begin{tabular}{|c|c|c|c|c|c|}
\hline \multirow[b]{2}{*}{ Item } & \multirow[b]{2}{*}{$n$} & \multicolumn{2}{|l|}{ Flavor } & \multicolumn{2}{|l|}{ Juiciness } \\
\hline & & liking & SEM $^{4}$ & liking & SEM \\
\hline \multicolumn{6}{|l|}{ Source } \\
\hline Texas establishments & 168 & 6.3 & 0.23 & 6.2 & 0.28 \\
\hline Non-Texas establishments & 170 & 6.3 & 0.22 & 6.2 & 0.21 \\
\hline$P$ value & & 0.665 & & 0.904 & \\
\hline \multicolumn{6}{|l|}{$\begin{array}{l}\text { USDA quality grade/ } \\
\text { brand category }\end{array}$} \\
\hline Top Choice & 118 & 6.4 & 0.23 & 6.4 & 0.27 \\
\hline Choice & 106 & 6.3 & 0.23 & 6.1 & 0.26 \\
\hline Select & 114 & 6.1 & 0.24 & 6.0 & 0.22 \\
\hline$P$ value & & 0.064 & & 0.236 & \\
\hline
\end{tabular}

${ }^{1}$ Consumers used the following 9-point scales: flavor liking $(1=$ dislike extremely; 9 = like extremely) and juiciness liking ( 1 = dislike extremely; $9=$ like extremely).

${ }^{2}$ Beef strip loins were obtained from Texas establishments or from NonTexas establishments (Kansas, Nebraska, or Colorado).

${ }^{3}$ USDA quality grade/brand category: Top Choice $=$ branded programs that require Modest and Moderate marbling scores to qualify; Choice = primarily Small marbling scores; Select $=$ Slight marbling.

${ }^{4}$ Standard error of the mean.

flavor ratings when steaks from these marbling scores have been evaluated. Emerson et al. (2013) reported greater meaty/brothy flavor ratings for steaks from marbling scores of Moderate and Modest compared with Small and Slight; for buttery/beef fat flavor 
ratings, significant differences between these marbling scores were Moderate $>$ Modest $>$ Small $>$ Slight. Lorenzen et al. (1999) found that Top Choice and Low Choice top loin steaks did not differ $(P>0.05)$ in flavor desirability ratings, with both of them greater than the High Select and Low Select steaks. Savell et al. (1987) reported that trained panel flavor intensity ratings were higher $(P<0.05)$ for steaks from Moderate and Modest marbling scores compared with Small, Slight+, Slight-, and Traces. In general, greater marbling scores positively influence flavor ratings, although in this study, differences were not found.

Source $\times$ USDA quality grade/brand category interactions for overall liking $(P=0.012)$ and tenderness liking $(P=0.002)$ can be found in Table 6 . Both overall liking and tenderness liking ratings for the Top Choice steaks from the Texas establishments drove the interaction in that these ratings did not differ $(P>0.05)$ from those from the Select steaks of either source, whereas Top Choice steaks from the Non-Texas establishments differed $(P<0.05)$ from their Select steak counterparts. Source did not influence $(P>0.05)$ the overall liking or tenderness liking ratings for Choice or Select steaks, which indicates that geographical establishment location should not be a consideration for those who wish to purchase beef products of these grades. However, it is of great concern that Top Choice steaks from Texas received the overall liking and tenderness liking ratings they did. Based on the findings of flavor liking and juiciness liking, the overall liking ratings for the Top Choice steaks from Texas were clearly influenced by the tenderness liking ratings. All of these ratings were quite high on 9-point scales; however, those purchasing beef from branded programs that feature Top Choice levels of marbling expect palatability above that of Choice and Select.

Even with a sex $\times$ marbling degree interaction, Emerson et al. (2013) found that, regardless of sex class (steer or heifer), steaks from Moderate and Modest marbling score degrees received higher tenderness ratings than steaks from Small or Slight marbling scores. Lorenzen et al. (1999) found that Top Choice steaks had greater $(P<0.05)$ overall like ratings than Low Choice, High Select, and Low Select steaks. Smith et al. (1985) documented that steaks from Moderate and Modest marbling scores received higher $(P<0.05)$ tenderness ratings than steaks from Small and Slight marbling scores. Studies such as these support that, for the most part, steaks from marbling scores of Modest or higher usually receive tenderness/overall consumer panelist ratings that are higher than steaks from marbling scores of Small or lower.

\section{WBS force}

There were no $(P=0.079)$ differences in WBS values for steaks from the 2 sources even though the $P$ value approached significance (Table 7). For USDA quality grade/brand category, there were differences $(P<0.001)$ in WBS values, but not in the direction one might expect. In this case, Choice steaks had the lowest $(P<0.05)$ WBS values compared with those from Top Choice and Select steaks, which did not differ $(P>0.05)$ from each other. These findings differ from previous work on WBS values and grade/marbling. Smith et al. (1985) found that WBS values from top

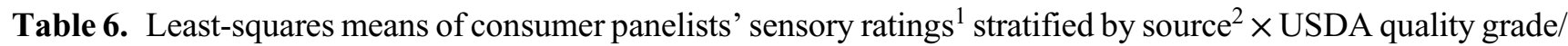
brand category ${ }^{3}$

\begin{tabular}{|c|c|c|c|c|c|c|}
\hline Source & USDA quality grade/brand category & $n$ & Overall liking & $\mathrm{SEM}^{4}$ & Tenderness liking & $\overline{\text { SEM }}$ \\
\hline Texas establishments & Top Choice & 58 & $6.1^{\mathrm{bc}}$ & 0.23 & $6.1^{\mathrm{bc}}$ & 0.20 \\
\hline Non-Texas establishments & Top Choice & 60 & $6.7^{\mathrm{a}}$ & 0.22 & $6.8^{\mathrm{a}}$ & 0.19 \\
\hline Texas establishments & Choice & 54 & $6.5^{\mathrm{ab}}$ & 0.23 & $6.7^{\mathrm{a}}$ & 0.20 \\
\hline Non-Texas establishments & Choice & 52 & $6.4^{\mathrm{abc}}$ & 0.23 & $6.6^{\mathrm{ab}}$ & 0.20 \\
\hline Texas establishments & Select & 56 & $6.3^{\mathrm{bc}}$ & 0.24 & $6.5^{\mathrm{abc}}$ & 0.20 \\
\hline Non-Texas establishments & Select & 58 & $6.0^{\mathrm{c}}$ & 0.22 & $6.1^{\mathrm{c}}$ & 0.20 \\
\hline$P$ value & & & 0.012 & & 0.002 & \\
\hline
\end{tabular}

${ }^{1}$ Consumers used the following 9-point scales: overall liking $(1=$ dislike extremely; $9=$ like extremely $)$ and tenderness liking $(1=\operatorname{dislike~extremely;~} 9=$ like extremely).

${ }^{2}$ Beef strip loins were obtained from Texas establishments or from Non-Texas establishments (Kansas, Nebraska, or Colorado).

${ }^{3}$ USDA quality grade/brand category: Top Choice = branded programs that require Modest and Moderate marbling scores to qualify; Choice = primarily Small marbling scores; Select $=$ Slight marbling.

${ }^{4}$ Standard error of the mean.

${ }^{\mathrm{a}-\mathrm{c}}$ Means within a column without a common superscript letter $\operatorname{differ}(P<0.05)$. 
Table 7. Least-squares means of WBS values stratified by source ${ }^{1}$ and USDA quality grade/brand category $^{2}$

\begin{tabular}{lccc}
\hline \hline Item & $n$ & WBS (N) & SEM $^{3}$ \\
\hline Source & & & \\
Texas establishments & 173 & 21.7 & 0.81 \\
Non-Texas establishments & 169 & 20.7 & 0.82 \\
$P$ value & & 0.079 & \\
USDA quality grade/brand category & & & \\
Top Choice & 117 & $21.3^{\mathrm{a}}$ & 0.89 \\
Choice & 112 & $19.5^{\mathrm{b}}$ & 0.86 \\
Select & 113 & $22.7^{\mathrm{a}}$ & 0.87 \\
$P$ value & & $<0.001$ & \\
\hline \multicolumn{1}{l}{ (1)ef } & & & \\
\end{tabular}

${ }^{1}$ Beef strip loins were obtained from Texas establishments or from NonTexas establishments (Kansas, Nebraska, or Colorado).

${ }^{2}$ USDA quality grade/brand category: Top Choice $=$ branded programs that require Modest and Moderate marbling scores to qualify; Choice = primarily Small marbling scores; Select $=$ Slight marbling.

${ }^{3}$ Standard error of the mean.

${ }^{\mathrm{a}, \mathrm{b}}$ Means within a column without a common superscript letter differ $(P$ $<0.05)$.

WBS, Warner-Bratzler shear.

loin steaks from Moderate and Modest marbling categories were lower than those from top loin steaks from the Small and Slight categories. Findings of Emerson et al. (2013) generally followed those of Smith et al. (1985) in that WBS values from top loin steaks with Moderate and Modest marbling scores did not differ $(P>0.05)$ and were significantly lower than for those steaks from the Small and Slight marbling categories. The WBS values reported by Savell et al. (1987) represent a greater range in marbling and exhibited a small but significant increase as marbling declined from Slightly Abundant to Traces with differences occurring when Moderate and Modest were compared to Slight.

Percentage distribution of WBS values according to the Belew et al. (2003) tenderness categories (Table 8) reveal that almost all of the values fell into the Very Tender or Tender groupings. The only WBS values that were in the Intermediate or Tough categories were those from the Select grade. Almost all of the Non-Texas Top Choice and Choice steaks had WBS values considered to be Very Tender, whereas the Texas Top Choice and Choice steaks had numerically more steaks in the Tender category than did the Non-Texas steaks. Compared with the concerns about Texas beef in the 1990s, the fact that we are highlighting slight differences in whether steaks were considered Very Tender or Tender between the 2 sources seems rather illogical. More recent National Beef Tenderness Surveys (Guelker et al., 2013; Martinez
Table 8. Percentage distribution of WBS values according to the tenderness categories based on Belew et al. (2003) and stratified by source ${ }^{1} \times$ USDA quality grade/brand category ${ }^{2}$

\begin{tabular}{|c|c|c|c|c|c|}
\hline Source & $\begin{array}{l}\text { USDA } \\
\text { quality } \\
\text { grade/ } \\
\text { brand } \\
\text { category }\end{array}$ & $\begin{array}{c}\text { Very } \\
\text { Tender, } \\
\text { WBS < } \\
31.4 \mathrm{~N} \\
(\%)\end{array}$ & $\begin{array}{c}\text { Tender, } \\
31.4 \mathrm{~N}< \\
\text { WBS }< \\
38.3 \mathrm{~N} \\
(\%)\end{array}$ & $\begin{array}{c}\text { Intermediate, } \\
38.3 \mathrm{~N}< \\
\text { WBS }<45.1 \\
\mathrm{~N}(\%)\end{array}$ & $\begin{array}{c}\text { Tough, } \\
\text { WBS > } \\
45.1 \mathrm{~N} \\
(\%)\end{array}$ \\
\hline $\begin{array}{l}\text { Texas } \\
\text { establishments }\end{array}$ & $\begin{array}{l}\text { Top } \\
\text { Choice }\end{array}$ & 89.7 & 10.3 & 0 & 0 \\
\hline $\begin{array}{l}\text { Non-Texas } \\
\text { establishments }\end{array}$ & $\begin{array}{l}\text { Top } \\
\text { Choice }\end{array}$ & 96.6 & 3.4 & 0 & 0 \\
\hline $\begin{array}{l}\text { Texas } \\
\text { establishments }\end{array}$ & Choice & 95.0 & 5.0 & 0 & 0 \\
\hline $\begin{array}{l}\text { Non-Texas } \\
\text { establishments }\end{array}$ & Choice & 100.0 & 0 & 0 & 0 \\
\hline $\begin{array}{l}\text { Texas } \\
\text { establishments }\end{array}$ & Select & 94.6 & 1.8 & 3.6 & 0 \\
\hline $\begin{array}{l}\text { Non-Texas } \\
\text { establishments }\end{array}$ & Select & 86.2 & 10.3 & 1.7 & 1.7 \\
\hline
\end{tabular}

${ }^{1}$ Beef strip loins were obtained from Texas establishments or from NonTexas establishments (Kansas, Nebraska, or Colorado).

${ }^{2}$ USDA quality grade/brand categories: Top Choice = branded programs that require Modest and Moderate marbling scores to qualify; Choice $=$ primarily Small marbling scores; Select $=$ Slight marbling

WBS, Warner-Bratzler shear.

et al., 2017) have shown that beef is more tender than beef from earlier surveys (Morgan et al., 1991; Brooks et al., 2000). Data from the present study show that tenderness ratings and WBS values are aligned with the recent National Beef Tenderness Surveys, and even though the Top Choice steaks from Texas establishments differed from the Top Choice steaks from Non-Texas establishments, these ratings and values certainly appear to be well within categories (Miller et al., 2001; Belew et al., 2003) thought to be very acceptable to the consuming public. In fact, the mean WBS force values $(19.5$ to $22.7 \mathrm{~N}$ ) for all source $\times$ USDA quality grade/brand categories are well below the Miller et al. (2001) threshold of $<29.4 \mathrm{~N}$ for $100 \%$ consumer acceptability.

\section{Thoughts about sources of beef}

Studies on the impact of geographic sources on beef palatability are limited. Rather than comparing geographic sources, several studies included beef from different US states possibly as a way to address concerns that may be raised by reviewers who might question where the beef was obtained. Emerson et al. (2013) obtained beef from establishments in Colorado, Kansas, Nebraska, and Texas. For the National 
Consumer Retail Beef Study, Savell et al. (1987) selected beef from establishments located in Texas, Kansas, Colorado, and Nebraska for the consumer evaluations that took place in San Francisco, Kansas City, and Philadelphia but only selected beef from Texas for the simulated retail phase conducted in Philadelphia and San Francisco (Savell et al., 1989). The Beef Customer Satisfaction studies (Neely et al., 1998; Lorenzen et al., 1999; Neely et al., 1999; Savell et al., 1999) included beef from establishments in Colorado, Texas, and Nebraska. Additionally, the beef quality studies reported by Smith et al. (1982), Smith et al. (1985), and Smith et al. (1987) used beef obtained from 8 establishments in 6 states. (Interestingly, based on our personal knowledge of these establishments and states from these studies, most of the establishments no longer exist, and 3 of the states no longer have large-scale beef packing plants.) It may be that sourcing beef from different geographic areas of the US may be important for some projects, such as marbling- or grade-related studies, and may be less important when studies are self-contained, such as when live animal trials or genetic assessments or when postmortem aging treatments are conducted. Geographic sources of beef may be a consideration but not necessarily a requirement for beef palatability research.

A valuable insight into the challenges of what geographic sources of beef really mean was given in the executive summary of the Beef Customer Satisfaction Study (National Live Stock and Meat Board, 1995). As mentioned previously (Neely et al., 1998; Lorenzen et al., 1999; Neely et al., 1999; Savell et al., 1999), that study selected beef from establishments in Texas, Colorado, and Nebraska. The investigators were able to gather some information from the production lots that carcasses were selected from, including where the feeder cattle originated. The 600 beef carcasses used in that study were from cattle that were originally from 16 different states, Mexico, and Canada (National Live Stock and Meat Board, 1995). This finding reveals some of the issues related to geographic sourcing at beef packing establishments in which, even though most of steer and heifer feeding may occur in the North and South Central states, feeder cattle may come from a wide variety of states and from neighboring countries.

\section{Conclusions}

The objective of the present study was to determine whether geographic source played a role in beef palatability, especially for premium-branded products such as those referred to as Top Choice. Top Choice steaks from Texas establishments did differ (lower tenderness and overall liking ratings) from steaks of the same grade originating from Non-Texas establishments. There is no real explanation for this difference.

Geographic source did not play a role in consumer sensory panel ratings or WBS values for Choice or Select steaks. Beef purchasers of these grade categories should not be concerned about source contributing to variation in palatability. Purchasing biases related to geographic sources of beef may remain, but this palatability information will assist those interested in making informed decisions.

\section{Acknowledgements}

This study was supported, in part, by the Texas Beef Council.

\section{Literature Cited}

American Meat Science Association. 2016. Research guidelines for cookery, sensory evaluation, and instrumental tenderness measurements of meat. American Meat Science Association, Champaign, IL. http://meatscience.org/docs/default-source/ publications-resources/amsa-sensory-and-tenderness-evaluationguidelines/research-guide/amsa-research-guidelines-for-cookeryand-evaluation-1-02.pdf?sfvrsn=2. (Accessed 3 June 2020.)

Belew, J. B., J. C. Brooks, D. R. McKenna, and J. W. Savell. 2003. Warner-Bratzler shear evaluations of 40 bovine muscles. Meat Sci. 64:507-512. https://doi.org/10.1016/S0309-1740 (02)00242-5.

Brooks, J. C., J. B. Belew, D. B. Griffin, B. L. Gwartney, D. S. Hale, W. R. Henning, D. D. Johnson, J. B. Morgan, F. C. Parrish, Jr., J. O. Reagan, and J. W. Savell. 2000. National Beef Tenderness Survey-1998. J. Anim. Sci. 78:1852-1860. https://doi.org/10.2527/2000.7871852x.

Certified Angus Beef LLC. c2021. Certified Angus Beef®. Certified Angus Beef LLC, Wooster, Ohio. https://www. certifiedangusbeef.com. (Accessed 27 May 2020.)

Emerson, M. R., D. R. Woerner, K. E. Belk, and J. D. Tatum. 2013. Effectiveness of USDA instrument-based marbling measurements for categorizing beef carcasses according to differences in longissimus muscle sensory attributes. J. Anim. Sci. 91:1024-1034. https://doi.org/10.2527/jas.2012-5514.

Guelker, M. R., A. N. Haneklaus, J. C. Brooks, C. C. Carr, R. J. Delmore, Jr., D. B. Griffin, D. S. Hale, K. B. Harris, G. G. Mafi, D. D. Johnson, C. L. Lorenzen, R. J. Maddock, J. N. Martin, R. K. Miller, C. R. Raines, D. L. VanOverbeke, L. L. Vedral, B. E. Wasser, and J. W. Savell. 2013. National Beef Tenderness Survey-2010: Warner-Bratzler shear force values and sensory panel ratings for beef steaks from United States retail and food service establishments. J. Anim. Sci. 91:1005-1014. https://doi.org/10.2527/jas.20125785 . 
Huffman, R. D., S. E. Williams, D. D. Hargrove, D. D. Johnson, and T. T. Marshall. 1990. Effects of percentage Brahman and Angus breeding, age-season of feeding and slaughter end point on feedlot performance and carcass characteristics. J. Anim. Sci. 68:2243-2252. https://doi.org/10.2527/1990. 6882243x.

Lorenzen, C. L., T. R. Neely, R. K. Miller, J. D. Tatum, J. W. Wise, J. F. Taylor, M. J. Buyck, J. O. Reagan, and J. W. Savell. 1999. Beef customer satisfaction: Cooking method and degree of doneness effects on the top loin steak. J. Anim. Sci. 77:637-644. https://doi.org/10.2527/1999.773637x.

Luchak, G. L., R. K. Miller, K. E. Belk, D. S. Hale, S. A. Michaelsen, D. D. Johnson, R. L. West, F. W. Leak, H. R. Cross, and J. W. Savell. 1998. Determination of sensory, chemical and cooking characteristics of retail beef cuts differing in intramuscular and external fat. Meat Sci. 50:55-72. https://doi.org/10.1016/S0309-1740(98)00016-3.

Martinez, H. A., A. N. Arnold, J. C. Brooks, C. C. Carr, K. B. Gehring, D. B. Griffin, D. S. Hale, G. G. Mafi, D. D. Johnson, C. L. Lorenzen, R. J. Maddock, R. K. Miller, D. L. VanOverbeke, B. E. Wasser, and J. W. Savell. 2017. National Beef Tenderness Survey-2015: Palatability and shear force assessments of retail and foodservice beef. Meat Muscle Biol. 1:138-148. https://doi.org/10.22175/ mmb2017.05.0028.

Miller, M. F., M. A. Carr, C. B. Ramsey, K. L. Crockett, and L. C. Hoover. 2001. Consumer thresholds for establishing the value of beef tenderness. J. Anim. Sci. 79:3062-3068. https://doi. org/10.2527/2001.79123062x.

Morgan, J. B., J. W. Savell, D. S. Hale, R. K. Miller, D. B. Griffin, H. R. Cross, and S. D. Shackelford. 1991. National Beef Tenderness Survey. J. Anim. Sci. 69:3274-3283. https:// doi.org/10.2527/1991.6983274x.

National Live Stock and Meat Board. 1995. Beef Customer Satisfaction: Report to the industry-A comprehensive inhome test among frequent beef consumers. National Live Stock and Meat Board with Texas A\&M University, Colorado State University, and Yankelovich Partners, Inc., Chicago, IL. https://agrilife.org/meat/files/2020/06/BeefCustomer-Satisfaction-report.pdf. (Accessed 2 June 2020.)

Neely, T. R., C. L. Lorenzen, R. K. Miller, J. D. Tatum, J. W. Wise, J. F. Taylor, M. J. Buyck, J. O. Reagan, and J. W. Savell. 1998. Beef Customer Satisfaction: Role of cut, USDA quality grade, and city on in-home consumer ratings. J. Anim. Sci. 76:10271033. https://doi.org/10.2527/1998.7641027x.

Neely, T. R., C. L. Lorenzen, R. K. Miller, J. D. Tatum, J. W. Wise, J. F. Taylor, M. J. Buyck, J. O. Reagan, and J. W. Savell. 1999. Beef Customer Satisfaction: Cooking method and degree of doneness effects on the top round steak. J. Anim. Sci. 77:653-660. https://doi.org/10.2527/1999.773653x.

North American Meat Institute. 2014. The meat buyer's guide ${ }^{\mathrm{TM}} .8$ th ed. North American Meat Institute, Washington, DC.

Pringle, T. D., S. E. Williams, B. S. Lamb, D. D. Johnson, and R. L. West. 1997. Carcass characteristics, the calpain proteinase system, and aged tenderness of Angus and Brahman crossbred steers. J. Anim. Sci. 75:2955-2961. https://doi.org/10.2527/ 1997.75112955x.

Reiman, M. 2019. Certified Angus Beef $®$ brand marks 15 consecutive years of growth: Record supply allows partners to meet consumer demand. Certified Angus Beef LLC, Wooster, $\mathrm{OH}$. https://www.cabcattle.com/certified-angus-beef-brandmarks-15th-consecutive-year-of-growth/. (Accessed 27 May 2020.)

Savell, J. W., R. E. Branson, H. R. Cross, D. M. Stiffler, J. W. Wise, D. B. Griffin, and G. C. Smith. 1987. National Consumer Retail Beef Study: Palatability evaluations of beef loin steaks that differed in marbling. J. Food Sci. 52:517-519. https://doi. org/10.1111/j.1365-2621.1987.tb06664.x.

Savell, J. W., H. R. Cross, J. J. Francis, J. W. Wise, D. S. Hale, D. L. Wilkes, and G. C. Smith. 1989. National Consumer Retail Beef Study: Interaction of trim level, price and grade on consumer acceptance of beef steaks and roasts. J. Food Quality. 12:251-274. https://doi.org/10.1111/j.1745-4557.1989. tb00328.x.

Savell, J. W., D. S. Hale, W. W. Morgan, K. Grones, S. J. Boleman, M. F. Miller, M. Springer, J. C. Brooks, C. R. Kerth, M. A. Carr, T. L. Wheeler, and S. Harper. 1996. Texas Perception Study: Evaluating beef based on geographic origin. Texas A\&M University, College Station, TX. https://meat.tamu. edu/files/2020/05/Texas-Perception-Study.pdf. (Accessed 20 June 2020.)

Savell, J. W., C. L. Lorenzen, T. R. Neely, R. K. Miller, J. D. Tatum, J. W. Wise, J. F. Taylor, M. J. Buyck, and J. O. Reagan. 1999. Beef Customer Satisfaction: Cooking method and degree of doneness effects on the top sirloin steak. J. Anim. Sci. 77:645-652. https://doi.org/10.2527/1999.773645x.

Sherbeck, J. A., J. D. Tatum, T. G. Field, J. B. Morgan, and G. C. Smith. 1996. Effect of phenotypic expression of Brahman breeding on marbling and tenderness traits. J. Anim. Sci. 74:304-309. https://doi.org/10.2527/1996.742304x.

Smith, G. C., Z. L. Carpenter, H. R. Cross, C. E. Murphey, H. C. Abraham, J. W. Savell, G. W. Davis, B. W. Berry, and F. C. Parrish, Jr. 1985. Relationship of USDA marbling scores to palatability of cooked beef. J. Food Quality. 7:289-308. https://doi.org/10.1111/j.1745-4557.1985.tb01061.x.

Smith, G. C., H. R. Cross, Z. L. Carpenter, C. E. Murphey, J. W. Savell, H. C. Abraham, and G. W. Davis. 1982. Relationship of USDA maturity scores to palatability of cooked beef. J. Food Sci. 47:1100-1107. https://doi.org/10.1111/j.13652621.1982.tb07627.x.

Smith, G. C., J. W. Savell, H. R. Cross, Z. L. Carpenter, C. E. Murphey, G. W. Davis, H. C. Abraham, F. C. Parrish, Jr., and B. W. Berry. 1987. Relationship of USDA quality grades to palatability of cooked beef. J. Food Quality. 10:269-286. https://doi.org/10.1111/j.1745-4557.1987.tb00819.x.

USDA. 2014. Institutional Meat Purchase Specifications: Fresh beef-Series 100. United States Department of Agriculture, Agricultural Marketing Service, Washington, DC. https:// www.ams.usda.gov/sites/default/files/media/IMPS_100_ Fresh_Beef\%5B1\%5D.pdf. (Accessed 21 July 2020.)

USDA. 2017. United States standards for grades of carcass beef. Agricultural Marketing Service, United States Department of Agriculture, Washington, DC. https://www.ams.usda. gov/sites/default/files/media/CarcassBeefStandard.pdf. (Accessed 21 July 2020.)

USDA. 2020a. Meat, poultry and egg product inspection directory. Food Safety and Inspection Service, United States Department of Agriculture. https://origin-www.fsis.usda.gov/ 
wps/portal/fsis/topics/inspection/mpi-directory. (Accessed 27 May 2020.)

USDA. 2020b. National weekly boxed beef cuts for branded products - negotiated sales. USDA Livestock, Poultry and Grain Market News, Des Moines, IA. https://www.ams.usda.gov/ mnreports/ams_2457.pdf. (Accessed 9 September 2020.)

USDA. 2020c. National weekly direct slaughter cattle - premiums and discounts. USDA Livestock, Poultry, and Grain Market News Division, St. Joseph, MO. https://www.ams.usda.gov/ mnreports/lm_ct155.txt. (Accessed 9 September 2020.)
USDA. [date unknown]. Certified beef programs. Agricultural Marketing Service, United States Department of Agriculture, Washington, DC. https://www.ams.usda.gov/ services/auditing/certified-beef-programs. (Accessed 26 May 2020.)

Whipple, G., M. Koohmaraie, M. E. Dikeman, J. D. Crouse, M. C. Hunt, and R. D. Klemm. 1990. Evaluation of attributes that affect longissimus muscle tenderness in Bos taurus and Bos indicus cattle. J. Anim. Sci. 68:2716-2728. https://doi.org/ $10.2527 / 1990.6892716 x$. 